\title{
Analisis Teknik Dasar Pukulan Dalam Permainan Bulutangkis
}

\author{
Ari Subarkah ${ }^{1}$, Ika Novitaria Marani ${ }^{2}$ \\ ${ }^{1}$ Fakultas Ilmu Keolahragaan, Universitas Negeri Jakarta, Indonesia \\ ${ }^{2}$ Universitas Negeri Jakarta, Indonesia. \\ E-mail:arytarakan2008@gmail.com¹, ikanovi1979@gmail.com²
}

Menerima: 30, Agustus,2020; Revisi: 20, Oktober, 2020; Diterima: 23, Oktober, 2020
https://doi.org/10.24036/MensSana.050220.02

\begin{abstract}
The objectives of this study were to determine: 1. Basic techniques of striking in a badminton game, and 2. The dominant stroke basic techniques are used in badminton games. The research method used in this research is descriptive research using survey techniques. The study population was all players who participated in the 2019 HSBC World Tour Final badminton match. While the sampling technique used was purposive, so the sample used was the Indonesian men's doubles pair who participated in that event. The data collection technique was carried out by observing the video on Youtube at the 2019 HSBC World Tour Final badminton match and then entering it into a table adapted to the basic techniques of playing badminton during the match. used is descriptive statistical analysis techniques. The results of this study are 1. The basic techniques of overhead hitting are 26\%, netting hits are 19\%, drive hits are $37 \%$ and service hitting is 18\%. 2. The basic technique of hitting that is dominant in badminton at the 2019 HSBC World Tour Final is the drive forehand. So it is advisable for coaches to always practice to practice all basic techniques of strokes, especially basic techniques of strokes that are considered to be deadly to the opponent so that they can win badminton matches.
\end{abstract}

Keywords: Basic Techniques of strokes, Games, Badminton

Abstrak

Tujuan dari penelitian ini adalah untuk mengetahui: 1 . Teknik dasar pukulan dalam permainan bulutangkis, dan 2. Teknik dasar pukulan yang dominan digunakan dalam permainan bulutangkis. Metode penelitian yang digunakan dalam penelitian ini adalah penelitian deskriptif dengan menggunakan teknik survei. Populasi penelitian adalah semua pemain yang mengikuti pertandingan bulutangkis HSBC World Tour Final Tahun 2019. Sedangkan teknik sampling yang digunakan adalah teknik purposive sampling, sehingga sampel yang digunakan adalah pasangan ganda putra Indonesia yang mengikuti pertandingan tersebut. Teknik pengambilan data dilakukan dengan cara melakukan pengamatan video yang ada di Youtube pada pertandingan bulutangkis HSBC World Tour Final Tahun 2019 dan kemudian memasukkannya ke dalam tabel yang disesuaikan dengan teknik dasar bermain bulutangkis yang dilakukan selama pertandingan. Teknik analisis data yang digunakan adalah teknik analisis statistic deskriptif. Adapun hasil dari penelitian ini adalah: 1. Teknik dasar pukulan overhead sebanyak $26 \%$, pukulan netting sebanyak $19 \%$, pukulan drive sebanyak $37 \%$ dan pukulan service sebanyak $18 \%$. 2. Teknik dasar pukulan yang dominan digunakan dalam permainan bulutangkis pada pertandingan bulutangkis HSBC World Tour Final Tahun 2019 adalah pukulan drive forehand. Sehingga disarankan kepada para pelatih untuk selalu melakukan latihan untuk melatih semua teknik dasar pukulan terutama teknik dasar pukulan yang dianggap bisa mematikan lawan sehingga bisa memenangkan pertandingan bulutangkis.

Kata Kunci: Teknik Dasar Pukulan, Bulutangkis

\section{PENDAHULUAN}

Prestasi yang dicapai oleh cabang olahraga bulutangkis, maka cabang olahraga bulutangkis di
Indonesia menjadi salah satu cabang olahraga yang sangat digemari oleh seluruha kalangan masyarakat mulai dari anak - anak hingga orang 
dewasa. Cabang olahraga bulutangkis merupakan olahraga permainan yang bersifat individual.

Bulutangkis merupakan olahraga yang menggunakan raket dalam permainannya yang dimainkan oleh dua orang atau empat orang dengan posisi berada di bidang lapangan yang berbeda yang dibatasi oleh jaring (net) (Aksan 2016). Dua orang untuk kategori permainan tunggal, dan untuk empat orang untuk kategori permainan ganda dan campuran.

$\mathrm{Hal}$ ini seperti yang diungkapkan Subardjah yang menyatakan bahwa permainan bulutangkis merupakan permainan individual, yang dapat dimainkan dengan cara satu lawan satu yang disebut dengan permainan tunggal, dan dua orang (berpasangan) melawan dua orang (berpasangan) yang disebut dengan ganda dengan menggunakan raket sebagai alat untuk memukul dan shuttlecock sebagai obyek yang dipukul (Grice 2007).

Atau bisa dikatakan bahwa shuttlecock yang dimainkan tidak dipantulkan ke lantai dan harus dimainkan di udara, sehingga pada permainan ini dibutuhkan gerak reflek yang baik dan tingkat kebugaran yang tinggi. Lapangan bulutangkis memiliki bentuk persegi panjang, dengan lebar lapangan 6.10 meter dan panjang 13.40 meter.

Pada lapangan bulutangkis terdiri atas garis servis, garis pinggir, garis tengah dan dibatasi oleh net yang memiliki ukuran tinggi 1.55 meter (Nuzul Fitra, Sifu 2020). Lapangan permainan bulutangkis untuk kategori tunggal, ganda dan campuran berbeda.

Pada saat permainan terjadi, untuk permainan kategori tunggal, shuttlecock yang jatuh di dalam garis pinggir paling dalam dianggap masuk dan pemain yang melakukan service yang mendapatkan angka. Sedangkan shuttlecock yang jatuh diluar garis pinggir paling dalam dianggap keluar dan dapat yang mendapatkan angka adalah lawannya.

Namun terjadi perbedaan untuk kategori ganda (baik putra, putri maupun campuran), shuttlecock dianggap keluar apabila shuttlecock jatuh di luar garis lapangan paling pinggir lapangan (garis lapangan yang kedua). Terjadi perbedaan pula pada kategori tunggal maupun ganda pada saat melakukan service.

Pada kategori tunggal, shuttlecock dianggap masuk apabila shuttlecock jatuh di daerah kotak yang mulai dari garis pertama setelah net, garis pinggir lapangan yang pertama (kanan/kiri) hingga garis paling belakang.
Sedangkan untuk kategori ganda (baik putra, putri maupun campuran), shuttlecock dianggap masuk apabila shuttlecock jatuh di daerah kotak yang dimulai dari garis pertama setelah net, garis lapangan paling pinggir (kanan maupun kiri) hingga garis kedua yang ada di bagian belakang lapangan.

Tujuan dari permainan bulutangkis adalah berusaha untuk menjatuhkan shuttlecock di daerah permainan lawan dan berusaha agar lawan tidak dapat memukul shuttlecock di daerah permainan lawan dan berusaha agar lawan tidak dapat memukul shuttlecock dan menjatuhkan di daerah permainan sendiri.

Karena saat permainan berlangsung, maka masing - masing pemain harus berusaha agar shuttlecock tidak menyentuh lantai di daerah permainan sendiri. Atau dengan kata lain, dapat dikatakan bahwa permainan pada cabang olahraga bulutangkis memiliki tujuan untuk mencetak poin dan mencegah lawan mencetak poin sehingga dapat memenangkan pertandingan. Oleh karena itu, cabang olahraga bulutangkis merupakan permainan yang membutuhkan kemampuan fisik, teknik, taktik dan mental bertanding yang baik.

Apabila shuttlecock jatuh di lantai atau menyangkut di net maka permainan berhenti (Subarjah, 2000). Sedangkan bila dilihat dari karakteristik gerak dan jenis keterampilan, seluruh gerakan yang ada dalam bulutangkis bersumber dari tiga keterampilan gerak dasar,

Gerak dasar adalah gerakan - gerakan dasar yang berkembangnya terjadi sejalan dengan pertumbuhan tubuh dan tingkat kematangan pada anak-anak. Gerak dasar merupakan pola gerakan yang menjadi dasar untuk ketangkasan gerak yang lebih kompleks (Mahendra 2017).

Bulutangkis juga merupakan olahraga permainan yang cepat dan membutuhkan gerak reflek yang baik dan tingkat kebugarannya yang tinggi (Grice 1999). Olahraga Bulutangkis merupakan olahraga permainan yang memiliki gerakan yang cepat secara terus menerus selama pertandingan, durasi yang lama dengan diselingi oleh waktu istirahat.

Sehingga bulutangkis merupakan aktivitas olahraga yang bercirikan intermiten dengan latihan intensitas tinggi yang lama (Faude et al. 2007). Sehingga dapat dikatakan bahwa bulutangkis merupakan olahraga yang ditandai dengan berbagai aksi dengan durasi pendek dan intensitas tinggi yang ditambah dengan waktu istirahat yang singkat. Hal ini dapat dilihat pada 
jumlah pukulan yang digunakan selama permainan dapat sangat bervariasi sehingga memungkinkan banyak pilihan untuk melakukan berbagai taktik (Seth 2016).

Selama pertandingan, pemain diharuskan untuk mempertahankan level intensitas tinggi selama mungkin. Sehingga pengeluaran energi tergantung pada faktor morfologi pemain dan efisiensi perpindahan dalam bermain bulutangkis (Phomsoupha and D 2016).

Para pemain memusatkan perhatian pada shuttlecock dan lawan untuk mengantisipasi perpindahan mereka. Untuk dapat mempersiapkan diri dalam menerima pengembalian shuttlecock dari lawan yang tidak biasa dan mengejutkan membutuhkan keterampilan yang cukup untuk dapat melakukan pukulan atau pengembalian shuttlecock di sepanjanga permainan berlangsung (Phomsoupha and Laffaye 2015).

Untuk dapat sukses dalam bermain bulutangkis, diperlukan kecepatan, kekuatan, koordinasi, reaksi, naluri, keterampilan teknik bermain (Baron et al. 1992). Oleh karena itu, salah satau persyaratan untuk sukses dalam bermain bulutangkis diperlukan penguasaan teknik dasar bermain bulutangkis.

Teknik dasar olahraga bulutangkis harus betul - betul dipelajarai terlebih dahulu agar ketika bermain dapat melakukan teknik dasar dengan baik sehingga dapat menunjang atlet meraih kemenangan dari teknik yang dilakukannya. Karena salah satu penentu kemenangan dalam suatu pertandingan salah satunya ditentukan oleh penguasaan teknik dasar bermain dalam permainan bulutangkis.

Teknik adalah ketrampilan khusus yang harus dikuasai oleh pemain bulutangkis dengan tujuan untuk dapat mengembalikan shuttle cock dengan sebaik-baiknya (Islahuzzaman 2005). Dalam permainan bulu tangkis sangat membutuhkan keterampilan untuk menguasai teknik dasar permainannya seperti cara memegang raket, gerakan kaki (footwork) dan teknik dasar pukulan (Hendra Sutiyawan, Yunitaningrum, and Purnomo 2015).

Salah satu teknik dasar yang digunakan dalam permainan bulutangkis adalah teknik pukulan. Menurut Tohar "teknik pukulan adalah cara - cara melakukan pukulan dalam permainan bulutangkis dengan tujuan untuk menerbangkan shuttlecock ke bidang lapangan lawan (Tohar 2005). Dan dalam permainan bulutangkis terdapat beberapa keterampilan teknik pukulan antara lain: 1. Servis (service), 2. Pukulan dengan ayunan raket mendatar (Drive) dan 3. Pukulan dengan ayunan raket dari atas (Over Head) (Subardjah 2002).

Pukulan servis merupakan gerakan untuk memulai permainan dengan memukul shuttlecock ke sisi lapangan lawan dan merupakan modal awal untuk bisa memenangkan suatu pertandingan (Alhusin 2007). Ada beberapa jenis pukulan servis yaitu: servis pendek, dan servis flick. Sedangkan pukulan drive merupakan pukulan yang keras dan cepat yang arah datangnya shuttlecock mendatar. Pukulan drive biasanya digunakan pemain untuk melakukan serangan dan mengembalikan bola dengan cepat baik secara lurus maupun menyilang ke daerah lawan (Purnama 2010).

Untuk pukulan dari atas (overhead) terdiri dari pukulan lob, pukulan lob, pukulan dropshot dan pukulan Smash (Widodo 2017). Pukulan overhead lob adalah bola yang di pukul dari atas kepala, dimana posisi tubuh saat memukul shuttlecock berada di belakang lapangan (atau di garis belakang lapangan) dan diarahkan ke atas bagian belakang lapangan lawan (Bangkit 2014).

Tujuan dari pukulan overhead lob ini adalah untuk melakukan serangan ke belakang lapangan lawan sehingga lawan akan kesulitan untuk mengembalikan shuttlecock sehingga memberikan peluang kepada penerima shuttlecock untuk dapat melakukan antisipasi pengembalian shuttlecock yang lebih baik. Pukulan lob dapat digunakan untuk bertahan dan menyerang. Namun, perbedaanya terletak ppada trayek lambungan shuttlecock yang dilakukan. Sehingga pukulan lob bisa menjadi senjata yang ampuh atau menipu lawan (Asnaldi 2016)

Pukulan smash merupakan pukulan overhead (atas kepala) yang dilakukan mengarah ke bawah dan dilakukan dengan tenaga penuh. Tujuan utama dari pukulan smash adalah bentuk pukluan yang keras sehingga pukulan ini identic digunakan untuk mematikan lawan dan mendapatkan point (Rahmat n.d.).

Kemampuan yang dimiliki pemain bulutangkis perlu dilakukan pengamatan agar dapat mengembangkan rencana teknik, taktis, latihan. Salah satu cara yang diperlukan untuk dapat mengembangkan rencana teknik, taktis dan latihan adalah dengan melakukan analisis pola bermain (Laffaye, Phomsoupha, and Dor 2015). 
Oleh karena itu, perlunya dilakukan analisis pola bermain berdasarkan teknik dasar pukulan selama pertandingan, karena pemain diharuskan untuk dapat mempertahankan tingkat intensita permainan yang tinggi selama mungkin. Sehingga tentunya hal ini akan berdampak pada pengeluaran energy.

Hal ini tergantung pada faktor morfologi dan perpindahan pemain yang efisien. Karena para pemain memusatkan perhatian mereka pada shuttlecock dan lawan mereka untuk mengantisipasi perpindahan mereka untuk dapat mengantisipasi pukulan shuttlecock yang tidak terduga (Desporto. 2009).

Berdasarkan permasalahan di atas, maka dirasakan perlu untuk melakukan penelitian tentang penggunaan teknik dasar pukulan dalam permainan bulutangkis. Analisis ini tentunya nanti akan bermanfaat bagi pelatih untuk dapat menyusun strategi dan taktik, teknik serta fisik yang harus dipersiapkan ketika mereka menghadapi lawannya.

Oleh karena itu, peneliti tertarik untuk meneliti masalah tentang analisis teknik dasar pukulan dalam permainan bulutangkis. Dengan tujuan untuk mengetahui teknik dasar pukuan apa saja yang digunakan dalam permainan bulutangkis dalam suatu pertandingan dan teknik dasar pukulan dominan yang digunakan dalam permainan bulutangkis dalam suatu pertandingan.

\section{METODE}

Metode penelitian yang digunakan pada penelitian ini adalah metode deskriptif dengan menggunakan teknik survey dengan melakukan pengamatan pada pertandingan HSBC World Tour Final Tahun 2019. Adapun tujuan dari penelitian ini adalah untuk mengetahui: bagaimana penggunaan teknik dasar yang dilakukan dan dominan dilakukan dalam permainan bulutangkis pada atlit ganda putra Indonesia.

Pengambilan data dilakukan di Jakarta pada bulan Desember Tahun 2019. Adapun populasi penelitian ini adalah peserta pertandingan HSBC World Tour Final Tahun 2019. Sedangkan sampel yang digunakan adalah ganda putra Indonesia yang ikut pertandingan HSBC World Tour Final Tahun 2019 yaitu Pasangan Mohammad Ahsan dan Hendra Setiawan dengan menggunakan teknik purposive sampling.

Teknik pengambilan data dilakukan dengan cara melakukan pengamatan video yang ada di Youtube pada pertandingan bulutangkis HSBC World Tour Final Tahun 2019 dan kemudian memasukkannya ke dalam tabel yang disesuaikan dengan teknik dasar bermain bulutangkis yang dilakukan selama pertandingan HSBC World Tour Final Tahun 2019.

Adapun teknik dasar bermain bulutangkis yang diambil datanya adalah: teknik pukulan dan servis. Untuk teknik analisis data yang digunakan pada penelitian ini adalah dengan melakukan reduksi, penyajian lalu penarikan kesimpulan.

Reduksi data dilakukan dengan cara memilih dan menyederhanakan data mentah dari hasil pertandingan yang dilakukan oleh pasangan ganda putra Indonesia di setiap babaknya (mulai dari mereka bermain hingga mereka kalah). Setelah data hasil pertandingan di setiap babak direduksi, kemudian dilakukan penyajian data dalam bentuk tabel, grafik dan lain - lain.

Dan yang terakhir dilakukan adalah melakukan penarikan kesimpulan berdasarkan data yang disajikan dalam bentuk deskripsi kalimat yang singkat dan padat sehingga dapat memberikan makna terhadap data yang telah direduksi dan disajikan.

Tabel 1. Form Pengumpulan Data

\begin{tabular}{|c|c|c|c|c|c|c|c|c|c|}
\hline \multirow[t]{2}{*}{ No } & \multirow{2}{*}{$\begin{array}{l}\text { Nama } \\
\text { Atlet }\end{array}$} & \multicolumn{3}{|c|}{ Overhead } & \multicolumn{2}{|c|}{ Netting } & \multicolumn{2}{|c|}{ Drive } & Service \\
\hline & & Lob & Forehand & Backhand & Forehand & Forehand & Forehand & Backhand & Flick Short \\
\hline
\end{tabular}

\section{HASIL DAN PEMBAHASAN}

\section{Hasil Penelitian}

Penelitian ini bertujuan untuk mengkaji tentang persentase teknik dasar pukulan dalam permainan bulutangkis dan teknik dasar pukulan yang dominan dalam permainan bulutangkis yang digunakan pada pertandingan HSBC World Tour Final Tahun 2019. Deskripsi data hasil penelitian dimaksudkan untuk memberikan gambaran umum mengenai hasil pengolahan data yang di dapat dari hasil pengamatan yaitu pengamatan 
terhadap teknik dasar pukulan dalam permainan bulutangkis pada pertandingan HSBC World Tour Final Tahun 2019.

Adapun teknik dasar pukulan dalam permainan bulutangkis yang diamati yaitu teknik pukulan overhead, netting, drive dan service. Data yang dideskripsikan ini merupakan data yang diperoleh dari hasil observasi pada pemain ganda putra Indonesia yang mengikuti pertandingan HSBC World Tour Final Tahun 2019 dari babak awal hingga babak akhir (final), yaitu pasangan Mohammad Ahsan dan Hendra Setiawan.

Gambaran deskripsi data penelitian terdiri atas: nilai terendah, nilai tertinggi, median, mean,

\begin{tabular}{cccc}
\hline \multicolumn{2}{c}{ Teknik Dasar Pukulan } & Jumlah & Persentase \\
\hline \multirow{3}{*}{ Overhead } & Lob & 17 & $5 \%$ \\
& Smash & 239 & $70 \%$ \\
& Dropshot & 85 & $25 \%$ \\
\hline \multicolumn{2}{c}{ Total } & 341 & $100 \%$ \\
\hline \multirow{2}{*}{ Netting } & Forehand & 131 & $53 \%$ \\
& Backhand & 118 & $47 \%$ \\
\hline \multicolumn{2}{c}{ Total } & 249 & $100 \%$ \\
\hline \multirow{2}{*}{ Drive } & Forehand & 260 & $54 \%$ \\
& Backhand & 218 & $46 \%$ \\
\hline \multirow{2}{*}{ Service } & Total & 478 & $100 \%$ \\
\hline \multicolumn{2}{c}{ Flick } & 41 & $18 \%$ \\
\hline & Short & 189 & $82 \%$ \\
\hline
\end{tabular}

modus dan simpangan baku dari teknik dasar pukulan dalam permainan bulutangkis pada pertandingan HSBC World Tour Final Tahun 2019.

Adapun total keseluruhan babak dari awal hingga akhir dalam pertandingan pertandingan HSBC World Tour Final Tahun 2019 sebanyak 5 (lima) dan terdiri dari 11 set yang dimainkan oleh Mohammad Ahsan dan Hendra Setiawan. Semua babak dimainkan hanya dengan 2 (dua) straight set, hanya 1 (satu) babak yang dimainkan dengan adalah deksripsi data hasil penelitian dari data teknik dasar pukulan pada pertandingan HSBC World Tour Final Tahun 2019.

Data penelitian yang akan ditampilkan berikut ini adalah jumlah dan persentase dari teknik dasar pukulan dalam bermain bulutangkis pada pertandingan HSBC World Tour Final Tahun 2019.

Dimana data teknik dasar pukulan dalam bermain bulutangkis yang diambil adalah teknik pukulan overhead, netting, drive dan service. Teknik - teknik pukulan tersebut dibagi lagi menjadi beberapa bagian, seperti: teknik pukulan overhead terdiri dari pukulan lob, smash dan dropshot, teknik pukulan netting dan drive terdiri dari pukulan backhand dan forehand, sedangkan teknik pukulan service terdiri dari pukulan flick dan short.

Tabel 2. Deskripsi Data Hasil Penelitian

Berikut ini adalah gambaran data jumlah dan persentase dari masing - masing teknik dasar pukulan dalam bermain bulutangkis yang di bagi menurut macam - macam pukulannya selama pertandingan HSBC World Tour Final Tahun 2019.

\section{Tabel 3. Persentase Teknik Pukulan Dasar}

Tabel 3 menunjukkan bahwa pukulan overhead yang terdiri dari pukulan $l o b$ dilakukan sebanyak 17 kali pukulan atau sebesar 5\%, pukulan smash dilakukan sebanyak 239 atau sebesar $70 \%$ dan pukulan dropshot sebanyak 85 atau sebesar $25 \%$. Untuk pukulan netting yang terdiri dari pukulan forehand dilakukan sebanyak 131 atau $53 \%$ dan pukulan backhand dilakukan sebanyak 118 atau sebesar $47 \%$.

Untuk pukulan drive yang terdiri dari pukulan forehand dilakukan sebanyak 260

\begin{tabular}{cccccccc}
\hline \multirow{2}{*}{\begin{tabular}{c} 
Pukulan \\
\cline { 3 - 8 }
\end{tabular}} & Terendah & Tertinggi & $\begin{array}{c}\text { Deskripsi Data } \\
\text { Rata } \\
\text { rata }\end{array}$ & Median & Modus & $\begin{array}{c}\text { Std } \\
\text { deviasi }\end{array}$ \\
\hline \multirow{2}{*}{ Overhead } & Lob & 0 & 5 & 0.77 & 0 & 0 & 1.45 \\
& Smash & 4 & 21 & 10.86 & 10 & 10 & 4.44 \\
& Dropshot & 0 & 8 & 3.86 & 3 & 2 & 2.25 \\
\hline \multirow{2}{*}{ Netting } & Forehand & 3 & 13 & 5.95 & 5 & 4 & 2.46 \\
& Backhand & 1 & 10 & 5.36 & 4 & 3 & 3.16 \\
\hline \multirow{2}{*}{ Drive } & Forehand & 4 & 20 & 11.82 & 12 & 5 & 5.28 \\
& Backhand & 4 & 16 & 9.91 & 9 & 9 & 3.32 \\
\hline \multirow{2}{*}{ Service } & Flick & 0 & 5 & 1.86 & 2 & 2 & 1.32 \\
& Short & 6 & 11 & 8.59 & 9 & 9 & 1.47 \\
\hline
\end{tabular}

rubber game yaitu pada babak kedua. Berikut ini pukulan atau sebesar 54\% dan pukulan backhand 
dilakukan sebanyak 219 pukulan atau sebesar 46\%. Dan untuk pukulan service yang terdiri dari pukulan flick dilakukan sebanyak 41 pukulan atau $18 \%$ dan pukulan short dilakukan sebanyak 189 pukulan atau sebesar $82 \%$.

\section{Pembahasan}

Penelitian ini merupakan penelitian deskriptif yang mempunyai tujuan untuk mengetahui tentang persentase teknik dasar pukulan dalam permainan bulutangkis dan teknik dasar pukulan yang dominan dalam permainan bulutangkis yang digunakan selama pertandingan HSBC World Tour Final Tahun 2019. Data penelitian yang telah dideskripsikan di atas merupakan data hasil pertandingan HSBC World Tour Final Tahun 2019 yang memiliki keseluruhan game sebanyak 11 game dan terdiri dari 5 (lima) babak.

Adapun teknik dasar pukulan yang diambil datanya adalah teknik pukulan overhead, netting, drive dan service. Teknik dasar pukulan tersebut dibagi lagi ke dalam beberapa jenis, yaitu: pukulan overhead terbagi atas lob, smash dan dropshot. Untuk pukulan netting dan drive terdiri dari pukulan forehand dan backhand. Sedangkan untuk pukulan service terbagi atas pukulan flick dan short.

Hasil penelitian menunjukkan terdapat sebanyak 341 pukulan overhead yang diperoleh dari keseluruhan game yang telah dimainkan oleh pasangan ganda putra pada pertandingan HSBC World Tour Final Tahun 2019. Pukulan overhead terbagi lagi menjadi pukulan lob, smash dan dropshot. Hasil penelitian menunjukkan bahwa pukulan lob dilakukan sebanyak 17 pukulan, pukulan smash dilakukan sebanyak 239 pukulan dan pukulan dropshot dilakukan sebanyak 85 pukulan. Sehingga dapat dikatakan bahwa pukulan overhead yang paling banyak dilakukan oleh pasangan putra Indonesia selama pertandingan HSBC World Tour Final Tahun 2019 adalah pukulan smash sebesar 70\%.

Hal ini menandakan bahwa pukulan overhead smash merupakan salah satu pukulan overhead yang sering dilakukan oleh pasangan ganda putra Indonesia untuk mematikan lawan dan mendapatkan point. Teknik pukulan overhead smash merupakan bentuk serangan yang paling banyak dipergunakan dalam upaya memperoleh nilai atau angka oleh suatu tim. Pukulan smash merupakan tindakan memukul shuttlecock yang keras sehingga menggakibatkan pihak lawan sulit untuk mengembalikannya (Muhajir 2004). Sehingga pukulan overhead smash dapat dikatakan sebagai tembakan offensive yang dilakukan dari lapangan belakang lalu bergerak ke tengah lapangan agar bisa menyiapkan pukulan berikutnya (Jaitner 2007)

Berdasarkan hasil penelitian pukulan smash banyak dilakukan, ini berarti bahwa pemain harus cepat mempersiapkan posisi tubuh untuk berada di belakang lapangan agar dapat melakukan pukulan smash secara efektif. Pukulan ini dilakukan agar lawan tidak dapat mengembalikan shuttlecock ataupun jika mampu mengembalikan shuttlecock, posisi shuttlecock memberikan keuntungan bagi lawannya untuk melakukan pukulan lainnya yang mungkin bisa menghasilkan angka (Fadhil Abdullah et al. 2018).

Hasil penelitian untuk teknik dasar pukulan netting menunjukkan sebanyak 249 pukulan netting yang diperoleh dari keseluruhan game yang telah dimainkan oleh pasangan ganda putra pada pertandingan HSBC World Tour Final Tahun 2019. Pukulan netting terbagi lagi menjadi pukulan backhand dan forehand. Dan pukulan netting yang paling banyak dilakukan adalah pukulan netting forehand sebanyak 131 pukulan. Pukulan netting dimainkan oleh pemain bulutangkis di depan sehingga shuttlecock jatuh dan berputar tepat di atas net di lapangan lawan.

Hasil penelitian untuk teknik dasar pukulan drive menunjukkan sebanyak 478 pukulan drive yang diperoleh dari keseluruhan game yang telah dimainkan oleh pasangan ganda putra pada pertandingan HSBC World Tour Final Tahun 2019. Pukulan drive terbagi lagi menjadi pukulan backhand dan forehand. Dan pukulan drive yang paling banyak dilakukan adalah pukulan drive forehand sebanyak 26 Hasil penelitian untuk teknik dasar pukulan netting menunjukkan sebanyak 249 pukulan netting yang diperoleh dari keseluruhan game yang telah dimainkan oleh pasangan ganda putra pada pertandingan HSBC World Tour Final Tahun 2019.

Pukulan netting terbagi lagi menjadi pukulan backhand dan forehand. Dan pukulan netting yang paling banyak dilakukan adalah pukulan netting forehand sebanyak 131 pukulan. Pukulan netting dimainkan oleh pemain bulutangkis di depan sehingga shuttlecock jatuh dan berputar tepat di atas net di lapangan lawan. Hasil penelitian untuk teknik dasar pukulan 
drive menunjukkan sebanyak 478 pukulan drive yang diperoleh dari keseluruhan game yang telah dimainkan oleh pasangan ganda putra pada pertandingan HSBC World Tour Final Tahun 2019.

Pukulan drive terbagi lagi menjadi pukulan backhand dan forehand. Dan pukulan drive yang paling banyak dilakukan adalah pukulan drive forehand sebanyak 260 pukulan. Pukulan drive merupakan pukulan datar yang tidak terlalu jauh dari net. Pukulan drive merupakan pukulan tembakan serangan balik yang kuat dan cepat, dengan posisi raket harus dipegang dengan kepala menghadap lurus ke depan. Sedangkan hasil penelitian untuk teknik dasar pukulan service menunjukkan sebanyak 230 pukulan service yang diperoleh dari keseluruhan game yang telah dimainkan oleh pasangan ganda putra pada pertandingan HSBC World Tour Final Tahun 2019. Pukulan service terbagi lagi menjadi pukulan flick dan short. Dan pukulan service yang paling banyak dilakukan adalah pukulan service short sebanyak 189 pukulan.

Apabila dilihat dari hasil penelitian keseluruhan game yang telah dimainkan oleh pasangan ganda putra pada pertandingan HSBC World Tour Final Tahun 2019 terlihat bahwa teknik dasar pukulan dalam bermain bulutangkis yang paling banyak dilakukan adalah pukulan drive yaitu sebanyak 478 pukulan. Hal ini menunjukkan bahwa pasangan ganda putra Indonesia dominan melakukan pukulan drive pada pertandingan HSBC World Tour Final Tahun 2019 dan bisa menjadikan pukulan drive sebagai salah satu kekuatan yang dimiliki oleh pasangan ganda putra Indonesia. Karena dengan memiliki pukulan drive yang baik, dapat mempersingkat durasi reli pertandingan. Sehingga tentu akan menghemat tenaga, waktu dan energy dalam permainan bulutangkis (Arslanoglu, Senel, \& Aydogmus, 2014).

Hasil penelitian menunjukkan bahwa pukulan drive merupakan pukulan yang paling sering digunakan oleh pasangan ganda putra Indonesia pada saat bertanding di HSBC World Tour Final Tahun 2019. Hal ini juga menunjukkan bahwa posisi pemain bulutangkis ganda putra Indonesia berada di tengah lapangan. Karena pukulan drive merupakan pukulan yang dilakukan secara mendatar dan merupakan pukulan balik yang dilakukan dengan kuat dan cepat. Sehingga diperlukan konsistensi dalam melakukan pukulan drive untuk dapat melihat keberhasilan pukulan drive yang dilakukan (K.T. Lee 2005).

Hal ini dikarenakan pukulan drive yang baik akan dapat memaksa lawan untuk mengangkat bola pada saat pengembalian, sehingga posisi lawan berada pada posisi bertahan. Pukulan drive yang dilakukan dengan kecepatan dan ketepatan tinggi dapat mengakibatkan pengembalian shuttlecock semakin tipis dan cepat saat melewati net. Pukulan drive yang baik membantu pemain untuk berada posisi yang tidak tertekan oleh lawan, bahkan pukulan drive yang efektif dapat menjadi sebuah rangkaian serangan yang dapat mematikan jika dilakukan dengan tepat dan disertai kecepatan pukulan drive yang tinggi.

Berdasarkan dari hasil penelitian maka dapat dilihat bahwa bulutangkis memiliki ciri gerakan yang sporadic dengan intensitas sedang dan tinggi. Tentu ini berkaitan dengan tindakan repetitive dengan durasi pendek tetap memiliki intensitas tinggi (Cabello Manrique and González-Badillo 2003) (Ooi et al. 2009). Hasil penelitian di atas menunjukkan bahwa telah terjadi perubahan pola atau struktur permainan dalam bulutangkis yang disebabkan oleh adanya perubahan peraturan permainan. Meskipun tidak ditemukan perbedaan waktu pertandingan yang signifikan, namun waktu permainan rata - rata antara tunggal putra dan tunggal putri, ganda putra dan ganda putri meningkat (Alcock and Cable 2009). Namun sebaliknya, Chen and Chen mengungkapkan bahwa durasi pertandingan togal, waktu kinerja dan interval istirahat terjadi perubahan yang signifikan lebih rendah (Chen and Chen 2008). Perbedaan ini menunjukkan diperlukannya tingkat keterampilan dalam teknik yang lebih tinggi untuk level atlet yang lebih tinggi (kelas dunia).

Oleh karena itu, berdasarkan hasil penelitian yang diperoleh, maka diharapkan pelatih dan pemain bulutangkis untuk selalu memperhatikan teknik - teknik dasar dalam bermain bulutangkis terutama teknik dasar pukulan. Karena dengan memiliki teknik dasar pukulan yang baik akan memberikan pengaruh pada durasi atau waktu permainan, reli sehingga bisa mengakibatkan kemenangan bagi pemain bulutangkis tersebut. Adapun saran untuk penelitian lebih lanjut, agar dapat melakukan analisis tentang perbandingan teknik dasar antara kategori (seperti tunggal, ganda dan mix). 


\section{KESIMPULAN}

Berdasarkan hasil penelitian yang dilakukan maka dapat disimpulkan bahwa teknik pukulan yang sering digunakan dalam permainan bulutangkis pada pertandingan HSBC World Tour Final Tahun 2019 adalah pukulan drive forehand sebanyak 260 pukulan atau sebesar $20 \%$ dari keseluruhan total pukulan yang dilakukan dalam pertandingan pertandingan HSBC World Tour Final Tahun 2019.

Disarankan untuk penelitian selanjutnya dapat dilakukan penelitian yang serupa hanya saja menganalisis untuk teknik bermain dalam permainan bulutangkis lainnya dan juga melakukan perbandingan antara pemain putra dengan pemain putri serta tingkat kejuaraan yang diikuti oleh pemain.

\section{DAFTAR PUSTAKA}

Aksan, Hermawan. 2016. Mahir Bermain Bulutangkis. Bandung: NUANSA.

Alcock, Alison, and N. Tim Cable. 2009. "A Comparison of Singles and Doubles Badminton: Heart Rate Response, Player Profiles and Game Characteristics." International Journal of Performance Analysis in Sport 9(2): 228-37.

Alhusin, Syahri. 2007. Gemar Bermain Bulutangkis. Surakarta:CV Setiaji.

Arslanoglu, Erkal, Omer SENEL, and Mert Aydogmus. 2014. "Analysis of Badminton Competitions in 2012 London Olympics." Turkish Journal of Sport and Exercise 16(3): 55-55.

Asnaldi, Arie. 2016. "Hubungan Pendekatan Latihan Massed Practice Dan Distributed Practice Terhadap Ketepatan Pukulan Lob Pemain Bulutangkis." Jurnal MensSana 1(2): 20-26.

Bangkit, Febry Kusuma. 2014. Program Studi Pendidikan Guru Sekolah Dasar Penjas, Jurusan Pendidikan Olahraga, Fakultas Ilmu Keolahragaan Universitas Negeri Yogyakarta Tingkat Kemampuan Dasar Memukul Lob Permainan Bulutangkis Siswa Peserta Ekstrakurikuler Di SD Negeri Surojoyo Kecamatan Candimulyo
Kabupaten Magelang Tahun 2014.

Baron, R. et al. 1992. "Catecholaminic Excretion and Heart Rate as Factors of Psychophysical Stress in Table Tennis." International Journal of Sports Medicine 13(7): 501-5.

Cabello Manrique, D., and J. J. González-Badillo. 2003. "Analysis of the Characteristics of Competitive Badminton." British Journal of Sports Medicine 37(1): 62-66.

Chen, Hsin-lian, and Trevor C Chen. 2008. "T Emporal $S$ Tructure C Omparison Of The $N$ $E w$ And $C$ Onventional $S$ Coring $S$ Ystems For $M$ En ' $S B$ Adminton $S$ Ingles In $T$ Aiwan." 6(1): 34-43.

Desporto., Júlio. 2009. "Trends of Tactical Performance Analysis in Team Sports: Bridging the Gap between Research, Training and Competition." Revista Portuguesa de Ciências do Desporto 9(1): 81-89.

Fadhil Abdullah, Mohd et al. 2018. "Playing Pattern Analysis of Men's Single Badminton Matches." International Journal of Engineering \& Technology 7(2.15): 168.

Faude, Oliver et al. 2007. "Physiological Characteristics of Badminton Match Play." European Journal of Applied Physiology 100(4): 479-85.

Grice, Tony. 1999. 53 Bulutangkis Petunjuk Praktik Dan Untuk Pemula Lanjutan. Jakarta: PT Rajagrafindo Persada Jakarta.

. 2007. "Bulutangkis: Petunjuk Praktis Untuk Pemula Dan Lanjut." Departemen Pendidikan dan Kebudayaan Direktorat jenderal Pendidikan Tinggi Proyek Pembinaan Tenaga Kependidikan: Jakarta.

Hendra Sutiyawan, Tutur, Wiwik Yunitaningrum, and Edi Purnomo. 2015. "Keterampilan Teknik Dasar Pukulan Pada Proses Pembelajaran Bulu Tangkis.” Jurnal Pendidikan dan Pembelajaran 4(8): 1-15.

Islahuzzaman. 2005. "Analisis Teknik Dasar Pukulan Bulutangkis Game 21 Pada 
Tunggal Putra." Smart Sport 42(4): 1.

Jaitner, Thomas wolf gang. 2007. "Biomechanical Analysis of The Jump Smash Of German Elite Badminton Players.

K.T. Lee, W. Xie and K.C.Teh. 2005. "Notational Analysis of International Badminotn Competitions." : 387-90.

Laffaye, Guillaume, Michael Phomsoupha, and Frédéric Dor. 2015. "Changes in the Game Characteristics of a Badminton Match: A Longitudinal Study through the Olympic Game Finals Analysis in Men's Singles." Journal of Sports Science and Medicine 14(3): 584-90.

Mahendra, Agus. 2017. Modul Teori Belajar Mengajar Motorik. Bandung: FPOK UPI.

Muhajir. 2004. Jakarta, Erlangga Pendidikan Jasmani Teori Dan Praktek SMA.

Nuzul Fitra, Sifu, Muhammad Zaenal Arwih. 2020. "Studi Analisis Keterampilan Teknik Dasar Permainan Bulu Tangkis Pada Siswa Putra Peserta Ekstrakurikuler Smp N 3 Kapontori." Jurnal Penelitian Ilmu Keolahragaan (JOKER) 1(1): 35-47.

Ooi, Cheong Hwa et al. 2009. "Physiological Characteristics of Elite and Sub-Elite Badminton Players." Journal of Sports Sciences 27(14): 1591-99.

Phomsoupha, Michael, and D. 2016. "Déterminants Biomécanique, Physiologique et Modélisation Physique de La Performance En Badminton." Education. Université Paris Saclay (COmUE).

Phomsoupha, Michael, and Guillaume Laffaye. 2015. "The Science of Badminton: Game Characteristics, Anthropometry, Physiology, Visual Fitness and Biomechanics." Sports Medicine 45(4): 473-95.

Purnama, Sapta Kunta. 2010. Surakarta: Yuma Pustaka Kepelatihan Bulutangkis Modern.

Rahmat, Ade. "Pembelajaran Lempar Bola Atas Pada Mahasiswa Kelas A Pagi Semester Iv
Ikip-Pgri Pontianak Mengajar Adalah Membantu Mahasiswa Untuk Menjalani Proses Pertumbuhan Dan.” : 105-13.

Seth, Bipasa. 2016. "Determination Factors of Badminton Game Performance Bipasa." BiocheInternational Journal of Physical Education, Sports and Health 1(3): 20-22.

Subardjah, Herman. 2002. Bulutangkis. Jakarta: Dirjen Pendidikan Dasar dan Menengah.

Tohar. 2005. JIKIP Semarang. Semarang. Nasution, Olahraga Pilihan Bulutangkis.

Widodo, Achmad Khoirul Umam dan Achmad. 2017. "Analisis Keterampilan Teknik Bermain Pada Permaingan Tunggal Dan Ganda Putra Dalam Cabang Olahraga Bulutangkis.” Kesehatan Olahraga 05(03): $1-8$. 